\title{
Romanian Cultural Background and its Relevance for Cross-Cultural Management - A Comment
}

\author{
G. Ionescu
}

\section{The importance of the article's subject:}

The subject is of a great theoretical and practical importance, being a major concern in the field of management, in the context of European integration and the tendency towards forming a global, multicultural economy. The major interest of the international companies in investing in the Central and Eastern European former communist countries is well know. The business success of the foreign capital in this geographical area strongly depends on the international companies" capacity and willingness to "learn" the national and organisational cultural features. In this context, the article "Romanian Cultural Background and its Relevance for Cross-Cultural Management" could be viewed as a "cultural guide" for the foreign investors in Romania, with deep relevance for crosscultural management, being one of the few approaches of this kind.

\section{The article's content}

The article is structured in three parts flowing in the following logic: theoretical setting and creation of an original conceptual apparatus of cultural audit; application of the theoretical model on the Romanians cultural background and drawing some cultural features relevant for the Romanian managers behaviour.

In the part devoted to the theoretical framework, the authors remind the famous approaches of the culture and cultural audit from managerial perspective (Schein, Hofstede, Schwartz, Davis, Ouchi). The authors discover some common points in approaching the culture by some foreign contemporary authors and the philosophical system of the Romanian Lucian Blage (considered by the authors as a forerunner for some current culture analysing systems). In the authors view, the culture is a community's (nation, organisation) self consciousness. The culture's content is a set of values and its from is shown through a specific cultural style. The authors argue that the cultural style might be described using five dimensions: spatial horizon, temporal horizon, emphasised values, orientation attitude and formative target of a culture. Using this conceptual apparatus, the authors imagine the Romanians cultural matrix, listing the essential cultural features coming out both from Romanian sociological research and foreigners opinion. In the final part of the article, some 
of the cultural features are developed in relevant aspects for organisational and managerial behaviour: organisation's perspective, organisation's attitude towards progress, communication style, work motivation, social mobility and social relationships, attitude towards religion a.s.o.

\section{Article's contributions}

The strongest point of the article is its authentic originality. The authors approach for the first time in the field literature the cultural model of Lucian Blaga, the single Romanian philosopher who has created his own philosophical system. Adapting the concept of stylistic matrix to the culture's analysis is real contribution of the authors to the cultural audit issue. In a limited space, the authors succeed in presenting a synthesis of the Romanians cultural matrix, easy to use by any foreign investor in the process of understanding the cultural background of their Romanian partners. The concept concerning a culture's dimensions are clearly defined and logically structured in a cultural pattern, described in a very coherent way. Speaking about the Romanians culture, that authors, also Romanians, succeed in avoiding effectively trap, meaning that their approaches is logical and rational (not an emotional one).

\section{Need for further research}

By its form and extent, the article "Romanian Cultural Background and its Relevance for Cross-Cultural Management" is nothing else but a "matrix" for further research. Has to be underlined that for a few years, the authors have a real interest in researching the cultural issues of management. The outcome of this interest consists of some empirical research and studies published in Romania and abroad. I also know that in this year the authors work on a project sponsored by the Romanian Ministry of Education, concerning the Romanian organisational culture's transformation, project which certainly they will apply the cultural audit pattern presented in this article. 